THU0730-HPR THE MAP OF THE RHEUMATOLOGY NURSE CLINICAL AND RESEARCH INTERVENTIONS IN THE VALENCIAN REGION (SPAIN)

Carmen Nájera Herranz ${ }^{1}$, Inés Cánovas Olmos ${ }^{1}$, Elena Grau García ${ }^{1}$, Amelia Carbonell Jordá ${ }^{2}$, Jenny de la Torre-Aboki ${ }^{3}$, Oscar Aranega Rodríguez ${ }^{4}$, Isabel Balaguer Trull ${ }^{5}$, Catalina Cano ${ }^{6}$, Carmen Maria Francés Amorós ${ }^{7}$, Lola Gil Gallego ${ }^{8}$, Alicia Gómez Clan ${ }^{9}$, Elizabeth Marín Martín ${ }^{10}, V^{2}$ Núñez-Monje ${ }^{11}$, Nieves Martinez Alberola ${ }^{10}$, Nurses Working Group of the Valencian Society of Rheumatology (GE-SVR). ${ }^{1}$ Rheumatology Department. HUP La Fe, Valencia, Spain; ${ }^{2}$ Rheumatology Department. H. San Juan, Alicante, Spain; ${ }^{3}$ Rheumatology Department. HGU Alicante, Alicante, Spain; ${ }^{4}$ Rheumatology Department. $H$ Vilajoyosa, Alicante, Spain; ${ }^{5}$ Rheumatology Department. HGU Valencia, Valencia, Spain; ${ }^{6}$ Rheumatology Department. H Marina Baixa, Alicante, Spain; ${ }^{7}$ Pediatric Rheumatology Department. HUP La Fe, Valencia, Spain; ${ }^{8}$ Rheumatology Department. H Alcoy, Alicante, Spain; ${ }^{9}$ Rheumatology Department. H Vinalopó, Alicante, Spain; ${ }^{10}$ Rheumatology Department. H Elda, Alicante, Spain; ${ }^{11}$ Rheumatology Department. HU Dr. Peset, Valencia, Spain

Background: There is none defined competences framework for Rheumatology Nursing at the moment in Spain. This fact leads to an heterogeneous roles and interventions in each Rheumatology department which has not ever been described nor quantified.

Objectives: To describe and quantify the rheumatology Nursing interventions in the Valencian Region (Spain).

Methods: A descriptive study was performed by the completion of an online questionnaire with a list of clinical and research intervention. The questionnaire was sent to the Head of Rheumatology Department of 33 public hospitals from the Valencian Region.

Results: 32 hospitals of the Valencian Region fulfilled the questionnaire: 15 from Valencia, 13 from Alicante and 4 from Castellón. $50 \%$ of the hospitals had a Rheumatology nurse. In those hospitals, $50 \%$ had only 1 Rheumatology nurse working at the moment. The maximum Rheumatology nurses working in the same hospitals were 4; 2 hospitals used to have a Rheumatology nurse but do not have it anymore at this moment. 11 hospitals have an auxiliary nurse ( 3 of them without nurses and 8 with nurses). The year of incorporation of the Rheumatology nurse in the Department was quite heterogeneous, being the earlier in 1992 and the last incorporation in 2017.

The nurses worked mainly in a Rheumatology department full time (68.75\%).

The $81 \%$ of the hospitals had an specific nursing agenda but only 7 hospitals had a monographic nurse-led clinic (osteoporosis nurse-led clinic $-25 \%$-, intravenous treatments nurse-led clinic $-12.5 \%$ - or cardiovascular risk nurse-led clinic $-6.25 \%$ )

Nurses clinical interventions are very heterogeneous covering the patient clinical management and practice nurses intervention activities. Nurses organized patient education workshops in $25 \%$ hospitals. In 11 hospitals, nurse undertook teaching activities. $56 \%$ participating in scientific workshops/congress, $44 \%$ teaching undergraduated nurses/registered nurses and $37.5 \%$ teaching other healthcare professionals.

In 11 hospitals, nurses undertook research activities. In 2 hospitals an specific research nurse was available. $56 \%$ of nurses participated in clinical trials, $50 \%$ participated in research projects and $50 \%$ participated in scientific congress. $25 \%$ of nurses lead research projects.

In 12 hospitals, nurses belong to a scientific society; in 11 hospitals, nurses participated in regional, national and/or international nurses working groups.

Conclusion: In at least $50 \%$ of the hospitals from the Valencian Region, nurse activity was registered. There are heterogeneous clinical activities performed by nurses. This fact raised the issue of the importance of having unified criteria for nurse's intervention and competences framework comparable in each and every hospital. Teaching and research were also a common interventions mentioned. These activities are necessary for a constant recycling and updating of the nurses and will help to gain the necessary visibility for the rheumatology nurses.

Disclosure of Interests: None declared

DOI: 10.1136/annrheumdis-2019-eular.5875

\section{THU0731-HPR "OSER ABORDER" SURVEY ON THE CROSSED NEEDS OF A BETTER UNDERSTANDING OF SEXUAL HEALTH ISSUES BETWEEN PATIENTS SUFFERING FROM CHRONIC INFLAMMATORY RHEUMATISMS AND HEALTHCARE PROFESSIONALS INVOLVED IN PATIENT THERAPEUTIC EDUCATION}

SAVEL Carine $^{1}$, Marie Sophie Cherillat ${ }^{2}$, Anne Marie Tronche ${ }^{3}$, Pauline Berland ${ }^{2}$, Candy Guiguet-Auclair ${ }^{4}$, Martin Soubrier ${ }^{1}$, Laurent Gerbaud ${ }^{5}$, Sandrine Malochet ${ }^{1}$. ${ }^{1}$ Chu Gabriel-Montpied, Rheumatology, Clermont-Ferrand, France; ${ }^{2}$ Chu GabrielMontpied, UTEP, Clermont-Ferrand, France; ${ }^{3}$ Chu Gabriel-Montpied, Psychiatry, Clermont-Ferrand, France; ${ }^{4}$ Chu Gabriel-Montpied, Public Health, ClermontFerrand, France; ${ }^{5}$ Chu Gabriel-Montpied, Clermont-Ferrand, France

Background: Chronic inflammatory rheumatisms (RIC) may negatively impact patients' sexual health and quality of life.

Overall, 31 to $76 \%$ patients suffering from rheumatoid arthritis (RA) report to suffer from sexual difficulties. Patients affected by spondyloarthritis $(\mathrm{SA})$ report a negative disease impact on sexual activity in 38 to $50 \%$ of cases. On the other hand, while healthcare professionals (HP) are well aware of the utility to approach this issue, most do not carry on with it for they feel insufficiently trained in this domain.

According to the 2015 EULAR recommendations, therapeutic patient education (TPE) is an essential part of patient management in the RIC domain. TPE actually does take into account the overall patient experience including sexuality.

A survey primarily focused on needs and conducted among patients and healthcare experts involved in TPE was thus deemed necessary to better define both the content and format of TPE to be delivered to HP in order to help them dialogue with their patients, while overcoming certain obstacles on this path.

Objectives: To define the educational needs of HP involved in TPE of patients suffering from CIR concerning sexual health issues.

Methods: Using an interdisciplinary team approach, we have elaborated two different questionnaires focused on assessing specific needs and designed for patients and healthcare professionals. These questionnaires were filled in online from May 2017 to November 2017 via a secured server implemented in each of the 14 French rheumatology centers by CIR patients, TPE-involved HP, and members of three patient associations.

Results: 239 patients answered the questionnaire $(60.7 \%$ suffering from $\mathrm{SA}, 6.7 \%$ from psoriasis rheumatism, and $32.6 \%$ from RA), as did 57 HP. Overall, $72 \%$ patients reported having suffered or being still suffering from sexual difficulties, whereas $80 \%$ of them had never approached the topic with their respective HP.

In $82 \%$ of cases, the patient claimed having addressed the issue, whereas $30 \%$ HPs reported having taken the initiative. Half of both the patients and HP reported they had not dared to approach the topic. To ease communication, HP would appreciate to "have a team specifically dedicated to particular sexual healthcare issues", "have specific tools available" and "undergo specific training sessions".

In line with HP answers, patients' primary expectations were to be heard and become well-informed. The people who were judged the most competent $(63 \%)$ and with whom patients would feel the most secure $(58 \%)$ were the psychologists. The topics thought to be the most useful by the patients were similar to those considered most useful for HP training, namely undesirable treatment effects on sexuality $(95 \%)$, impact of rheumatism on sexual activity (92\%), body image and chronic illness (81\%), partner communication (77\%), sexual dysfunctions $(77 \%)$, as well as physiology of aging and sexual function (75\%). About $70 \%$ HP expressed the need for complementary education, with $95 \%$ of them stressing the necessity to acquire further communications skills within this domain. Of these, $88 \%$ preferred short training sessions, and $80 \%$ group training sessions.

Conclusion: This survey clearly demonstrates the usefulness of implementing educational training, along with its appropriate content, among $\mathrm{HP}$, designed to enable them to approach sexual health issues and provide their patients with appropriate advices in this domain.

Acknowledgement: French Society of Rheumatology

Disclosure of Interests: None declared

DOI: 10.1136/annrheumdis-2019-eular.827 